Organizadora deste número

Colaboradores deste número

\section{VIVIANA GELADO}

Doutora em Teoria e história literária pela Universidade Estadual de Campinas (2004) e professora do Instituto de Letras da UFF. Foi pesquisadora visitante no Instituto de Estudios del Caribe da Universidad de Puerto Rico e no Centro de Investigaciones Literarias de Casa de las Américas (Cuba); bem como professora e pesquisadora visitante na Universidad Nacional Autónoma de México e em Northwestern University (EUA). Fez pós-doutorado em Princeton University. É membro do GT/ANPOLL "Relações literárias interamericanas" e Coordenadora do Grupo de Pesquisa "Afrolatinoamérica: estudos comparados" (CNPq). Publicou Poéticas da transgressão: vanguarda e cultura popular nos anos 20 na América Latina (Rio de Janeiro: 7Letras; São Carlos: EdUFSCar/FAPESP, 2006; Buenos Aires: Corregidor, 2008. Prêmio Jabuti, Crítica literária, 2007) e artigos em revistas especializadas (Revista de crítica literaria latinoamericana, Revista Iberoamericana, Gragoatá, Remate de males, entre outras). Organizou, com María Verónica Secreto, Afrolatinoamérica: estudos comparados (Rio de Janeiro: Mauad, 2016).

\section{ALEXANDRE FERNANDES CORRÊA}

Bacharel em Ciências Sociais: Antropologia na Universidade Federal do Rio de Janeiro (1986), Mestre em Antropologia Cultural na Universidade Federal de Pernambuco (1993), Doutor em Ciências Sociais (Antropologia) na Pontifícia Universidade Católica de São Paulo (2001) e Pós-doutorado em Antropologia, na Universidade Federal do Rio de Janeiro (2006). Segundo Pós-Doutorado em Antropologia (UERJ-2009). Atualmente é professor Associado III da Universidade Federal do Maranhão. Experiência na área de Antropologia Urbana eSociologia da Cultura, atuando nas seguintes áreas: Patrimônio Cultural, Memórias Sociais, Novos Patrimônios, Simbolismo e Imaginário, Arte e Literatura. Membro do Programa de Pós-Graduação em Cultura eSociedade (UFMA). Líder do Grupo de Pesquisas e Estudos Culturais (CRISOL). Membro do Conselho Estadual de Cultura do Maranhão (2008-9).

\section{ALEXANDRE JAIRO MARINHO MORAES}

Doutor e mestre em Ciência da Literatura e bacharel em Letras Português/Literatura pela Universidade Federal do Rio de Janeiro. Pós-doutor em Literatura Brasileira pela Universidade Federal Fluminense. Professor do Programa de Pós-Graduação em Letras/ UFES. Participa do Laboratório de Estudos de História Política e das Ideias e do Grupo de Pesquisa "Poesia: suportes formais de 
significação", ambos registrados no CNPq. Tem experiência nas áreas de Letras, com ênfase em Teoria Literária, Literatura Brasileira e literatura hispano-americana, atuando principalmente nos seguintes temas: modernidade e pós-modernidade, poesia contemporânea.

\section{ALFREDO CORDIVIOLA}

Licenciado em Letras pela Universidade de Buenos Aires (1986), Mestre em Teoria da Literatura pela UFPE (1993) e Doutor em Estudos Hispânicos e Latino-americanos pela University of Nottingham, Reino Unido (1998). Completou um pós-doutorado na Universidade de Buenos Aires (2012). Leciona no Departamento de Letras, na Licenciatura presencial e na Licenciatura à Distância, eno Programa de Pós-graduação em Letras da Universidade Federal de Pernambuco. Atualmente é professor titular em Teoria da Literatura. É também colaborador no Programa de Pós-graduação em Literatura e Interculturalidade da UEPB. Pesquisador do CNPQ, dirige o Grupo de pesquisa "Literatura hispano-americana colonial" desde 2004. Ocupa-se de um vasto conjunto de aspectos da literatura e da teoria, relativos em particular aos estudos latino-americanos, os estudos culturais e os estudos utópicos.

\section{ANA CLÁUDIA MUNARI DOMINGOS}

Professora do Mestrado em Leitura e Cognição da Universidade de Santa Cruz do Sul. Doutora em Letras pela Pontifícia Universidade Católica do Rio Grande do Sul (2011), na área de Teoria da Literatura. Linha de Pesquisa: Processos Narrativos Comunicacionais e Poéticos. Grupos de pesquisa: "Leitura, Literatura e Cognição"; "Intermídia" (CNPq); "Literatura, artes e mídias" (Anpoll). Projeto de pesquisa: "Vozes da ficção: o narrador na cultura da conexão". Atua principalmente nos seguintes temas: Teoria da Literatura; Literatura Comparada; Ficção contemporânea; Teorias da leitura; Formação do leitor e leitura; Literatura e mídias; Sistema literário e hipermídia; Convergência de mídias e hiperleitura.

\section{ANDRÉ FIORUSSI}

Graduou-se em Letras (Espanhol e Português) na Universidade de São Paulo (2003). Concluiu mestrado (2008) e doutorado (2013) no Programa de Pós-Graduação em Língua Espanhola e Literaturas Espanhola e Hispano-Americana da Universidade de São Paulo. Concluiu programa de Pós-Doutorado em Literatura Brasileira na Universidade de São Paulo (2014). Atualmente é Professor de Literaturas Hispânicas na Universidade Federal de Santa Catarina. Tem experiência na área de Letras, com ênfase em Literaturas 
Estrangeiras Modernas, atuando principalmente nos seguintes temas: Literaturas ibero-americanas, Modernismo hispanoamericano, Rubén Darío, Julio Herrera y Reissig, Sousândrade.

\section{ANTONIO BARROS DE BRITO JUNIOR}

Professor adjunto do Departamento de Linguística, Filologia e Teoria Literária da Universidade Federal do Rio Grande do Sul. Possui Licenciatura em Letras (2003), Mestrado em Teoria Literária (2006) e Doutorado em Teoria Literária (2010), todos pela Universidade Estadual de Campinas. Tem experiência na área de Letras, Linguística e Artes, com ênfase em Teoria Literária, Fundamentos e Crítica das Artes e da Literatura, Semiótica, Hermenêutica e Estética, atuando principalmente nos seguintes temas: Semiótica, Teoria Literária, Teoria da Vanguarda, Teoria da Interpretação do Texto Literário. Tem conhecimento da obra de Paul Ricoeur, Jacques Rancière, Charles S. Peirce, nas obras fundamentais da Fenomenologia, do Estruturalismo e da Estética do Século XX e, finalmente, nas obras romanescas e teórico-críticas de Umberto Eco.

\section{ANTONIO REDIVER GUIZZO}

Possui graduação em Letras pela Universidade Estadual do Oeste do Paraná, UNIOESTE, (2003), Pós-Graduação latu sensu pela Faculdade do Iguaçu em Lingua Portuguesa e Literatura (2006), Pós-Graduado em Métodos e Técnicas de Ensino pela UTFPR (2013), Mestrado em Letras - Área de Concentração: Linguagem e Sociedade; Linha de Pesquisa: Linguagem Literária e Interfaces Sociais - pela Universidade Estadual do Oeste do Paraná, UNIOESTE, (2009); Doutorado em Letras pela UNIOESTE de Cascavel (2014); Acadêmico do curso de Bacharel em Direito UNIOESTE de Marechal Cândido Rondon (2011) . Atualmente, é professor adjunto (dedicação exclusiva) da UNILA.

\section{AURORA GEDRA RUIZ ALVAREZ}

Mestre e Doutor em Letras (Literatura Portuguesa) pela Universidade de São Paulo. Possui Pós-Doutoramento pela Universidade de Indiana, nos Estados Unidos, em Estudos da Intermidialidade, área a que está vinculado o projeto de pesquisa que coordena: "Estudos da Intermidialidade: teorias e ensino". Docente do Curso de Letras e do Programa de Pós-Graduação em Letras da Universidade Presbiteriana Mackenzie. Suas linhas de pesquisa desenvolvem o interesse pelo estudo da Literatura Contemporânea e pelo estudo da Intermidialidade, especialmente no tratamento da relação entre o verbal e não-verbal. 


\section{AVANI SOUZA SILVA}

Possui graduação em Letras Clássicas e Vernáculas pela Universidade de São Paulo (1978), Licenciatura em Língua Portuguesa e Literaturas Portuguesa e Brasileira pela Faculdade de Educação da Universidade de São Paulo (1978), Especialização em Língua Portuguesa pela Pontifícia Universidade Católica de São Paulo (2001), mestrado e doutorado em Letras (Estudos Comparados de Literaturas de Língua Portuguesa) pela Universidade de São Paulo (2007 e 2015, respectivamente). Tem experiência na área de Letras com ênfase em Literatura dos Países de Língua Portuguesa e em Literatura Infantil e Juvenil, atuando principalmente nos seguintes temas: literaturas de Guimarães Rosa e de Mia Couto, Identidade Cultural, Linguagens do Imaginário, tradições orais crioulas preservadas pela Literatura de Cabo Verde e ressonância na Literatura Infantil e Juvenil, e formação de contadores de estórias crioulas.

\section{BRENO BATTISTIN SEBASTIANI}

Bacharel e Licenciado em História (1999), Mestre (2002) e Doutor (2006) em História Social pela USP. Professor Doutor de Língua e Literatura Grega do DLCV-FFLCH-USP desde 2002. Líder (com Daniel Rossi Nunes Lopes) do grupo de pesquisa "Gêneros de prosa greco-latina" desde 2013. Projeto de pesquisa em curso: "A vida mestra da história: fracasso e lucidez nos textos de Tucídides e Políbio" (2014-6).

\section{CIELO GRISELDA FESTINO}

Possui graduação em inglês pelo Instituto Nacional del Professorado Joaquín V. González (1983), mestrado em Língua e Literatura Inglesa pela Universidade de São Paulo (2000) e doutorado em Língua e Literatura em Inglês pela Universidade de São Paulo (2005). Atualmente é professor titular da Universidade Paulista. Tem pós-doutorado na área de ensino de literaturas estrangeiras pela Universidade de São Paulo/FAPESP (2007-2009) e pós-doutorado pela Universidade Federal de Minas Gerais (2010-2012) na área de narrativas pós-coloniais. Tem experiência na área de Letras, com ênfase em Literaturas de Língua Inglesa, atuando principalmente nos seguintes temas: literaturas de língua inglesa, com ênfase na literatura pós-colonial e ensino de literaturas estrangeiras.

\section{DUARTE BRAGA}

Possui Licenciatura em Línguas e Literaturas Modernas - Estudos Portugueses (2005), Mestrado (2009) e Doutoramento (2014) em Estudos Comparatistas, todos pela pela Universidade de Lisboa. 
No âmbito do Doutoramento recebeu bolsa da agência FCT (20092013) e realizou estágio de pesquisa na Universidade de WisconsinMadison (E.U.A.). Atuou como docente na Faculdade de Letras da U.L. e é investigador do Centro de Estudos Comparatistas da mesma Universidade. Desenvolve, no presente, pesquisa de pós-doutorado em Estudos Comparados de Literaturas de Língua Portuguesa na FFLCH-USP, com bolsa da FAPESP. Atua nas áreas de Literatura Portuguesa e Literatura Comparada. No momento, tem os seguintes interesses de pesquisa: poesia portuguesa do século $X X$, literatura finissecular, orientalismo na literatura portuguesa, literaturas de Goa e de Macau. Nestes campos organizou publicações de livros, eventos científicos e possui artigos em periódicos internacionais.

\section{ELLEN SPIELMANN}

Professora e pesquisadora em Teoria literária e cultural da América Latina, incluindo o Brasil, na Universidade de Tübingen (Alemanha). Suas pesquisas mais recentes são sobre contos latino-americanos (em particular, de Roberto Bolaño) e sobre escritores latino-americanos no exílio. É autora de, entre outros, Brasilianische Fiktionen: Gegenwart als Pastiche (1994), com estudos sobre Clarice Lispector, Jorge Amado, Darcy Ribeiro, Ignácio de Loyola Brandão e Silviano Santiago; e Der Blick des Axolote: Kultur-und literaturtheoretische Essays: Lateinamerika, Spanien und Portugal (2004); e editora de Teorías y formas de análisis de las relaciones entre globalidad y localidad en América Latina (1982-2005) (2007).

\section{ERNESTO MORA}

Pesquisador Colaborador do IEL/UNICAMP. Possui doutorado em Sociologia pela Universidade de São Paulo (2014), mestrado em Filosofia pela Pontificia Universidad Javeriana (2008) e graduação em Letras pela Universidad Nacional de Colombia (2003). Professor da Licenciatura en Filosofía y Lengua Castellana da Universidad Santo Tomás, nas áreas de Teoria literária, pragmática linguística e hermenêutica (2006-2009). Pesquisador nas áreas de sociologia da cultura, teoria social da narrativa e do discurso.

\section{FÁBIO ALMEIDA CARVALHO}

Mestre em Teoria da Literatura/UFPE (1998); doutor em Literatura Comparada/UFF (2011). Professor Associado da Universidade Federal de Roraima, onde atua no curso de Licenciatura Intercultural (graduação), no Programa de Pós-Graduação em Letras (PPGL/UFRR) e no Programa de Pós-Graduação em Sociedade e Fronteiras (PPGSOF/UFRR). Vem-se dedicando, 
principalmente, aos temas do estudo das trocas e transferências literárias e culturais e à problemática da interpretação do Brasil a partir do viés da crítica literária.

\section{GUSTAVO GUENZBURGER}

Pesquisador de teatro que trabalha desde 1989 também como ator, cantor, diretor e produtor. Produziu e atuou durante mais de vinte anos pelo Grupo Sarça de Horeb (1989-2011), que ajudou a fundar. Formou-se ator pela Casa das Artes de Laranjeiras (CAL - 1995). Possui graduação em Letras (Português/ Literatura) pela Universidade do Estado do Rio de Janeiro (2003). É mestre em Teoria e Literatura Comparada (2011) e Doutor em Literatura Comparada (2015), ambos também pela UERJ e com bolsa da CAPES. Em sua dissertação de mestrado abordou contradições na leitura tradicional que se faz da peça $O$ Mambembe, de Artur Azevedo, a partir de sua metaforologia e da recepção das montagens de 1904 e 1959. Em 2014 realizou estágio-sanduíche na Universidade Sorbonne Nouvelle (Paris III), como parte de sua pesquisa de doutorado sobre as relações entre a estética e a sócio-economia do teatro carioca. Atualmente é Bolsista Pós-doutorado Nota 10 da FAPERJ, em pesquisa desenvolvida no Programa de Pós-Graduação em Artes Cênicas da UNIRIO.

\section{HELANO RIBEIRO}

Possui licenciatura em Letras Português/Alemão pela Universidade Federal do Ceará (2005), mestrado (2011) e doutorado (2015) em Teoria da Literatura pela Universidade Federal de Santa Catarina. Trabalhou de 2006 a 2008 como professor leitor de Língua Portuguesa e Literatura Brasileira na Universidade de Colônia (Alemanha). Desenvolve trabalhos de literatura [e discursos totalitários] e teoria crítica dentro das temáticas literatura e ética, biopolítica, otobiografias e Walter Benjamin. É professor assistente de Língua Alemã na Universidade Federal de Pelotas, onde atua no Programa de Pós-Graduação em Letras. É editor da revista Caderno de Letras.

\section{HÉLDER GARMES}

Possui graduação em Linguística e em Letras pela Universidade Estadual de Campinas $(1983,1985)$, mestrado em Teoria e História Literária pela mesma universidade (1993), doutorado em Estudos Comparados de Literaturas de Língua Portuguesa pela Universidade de São Paulo (1999), tendo realizado estágios pós-doutorais na École des Hautes Études en Sciences Sociales (2005), em Paris, e no College of Humanities da Ohio State University (2009), em Columbus. 
Atualmente é professor livre-docente da Universidade de São Paulo, atuando especialmente nas áreas de literatura portuguesa, estudos comparados de literaturas de língua portuguesa e história da literatura. No momento, tem por foco dois núcleos de pesquisa: um voltado para a obra de Eça de Queirós; outro voltado para a literatura de língua portuguesa de Goa e de outras ex-colônias portuguesas do Oriente. É autor do livro Romantismo paulista (2006), organizador do volume Oriente, Engenho e Arte (2004), além de ser co-organizador de Literatura Portuguesa: História, Memória e Perspectivas (2007) e de um número especial da revista Via Atlântica (2011) sobre literatura e cultura em Goa, entre outras obras.

\section{JOÃO PAULO AYUB}

Graduado em Ciências Sociais e Mestre em Sociologia pela Universidade Federal de Minas Gerais (UFMG). Doutor em Ciências Sociais pela Universidade Estadual de Campinas (Unicamp). Pós-doutor em Estudos Literários pela Universidade Federal de Uberlândia (UFU). Professor substituto na Universidade Federal de Goiás/Regional Catalão. Tem experiência nas áreas de Sociologia, Antropologia, Estudos Literários e Ciência Política. Trabalhou com os temas do poder, biopolítica, governo de si e dos outros no pensamento de Michel Foucault durante a graduação em Ciências Sociais e Mestrado em Sociologia. Desenvolveu em sua Tese de Doutorado um estudo sobre a linguagem e a experiência na literatura de Graciliano Ramos. Projeto desenvolvido no estágio de pósdoutoramento: “Vidas à deriva: as rotas da exclusão em Lasar Segall e Moacyr Scliar". Atualmente realiza pesquisas nas áreas: Estudos Foucaultianos, Literatura e Pensamento Social, Cultura e Violência.

\section{LUANA ANTUNES COSTA}

É professora adjunta do Instituto de Humanidades e Letras da Universidade da Integração Internacional da Lusofonia Afrobrasileira (UNILAB/Redenção CE), doutora em Letras (Estudos Comparados de Literaturas de Língua Portuguesa), pela Universidade de São Paulo (2014), mestre em Letras (Literatura Portuguesa e Literaturas Africanas de Língua Portuguesa), pela Universidade Federal Fluminense (2008), bacharel e licenciada em Letras (Língua e Literatura Portuguesa e Francesa) pela Universidade Estadual Paulista (2005). Desenvolve pesquisa no campo das Literaturas de Língua Portuguesa e Literaturas Francófonas, com destaque para as relações entre Literatura e outros campos de saberes das Ciências Humanas, como História e Política; Literatura, corporeidade e autoria feminina; Literatura Comparada. 


\section{MANUEL ANTÔNIO DE CASTRO}

Professor Emérito de Poética da Universidade Federal do Rio de Janeiro. Possui graduação em Ciências Sociais pela Universidade Federal do Rio de Janeiro (1966), graduação em Letras Português/ Francês pela Universidade Federal do Rio de Janeiro (1969), graduação em Português/Alemão pela Universidade Federal do Rio de Janeiro (1997), graduação em Filosofia pela Faculdade de Filosofia dos Padres Franciscanos (1964), mestrado em Letras (Ciência da Literatura) pela Universidade Federal do Rio de Janeiro (1973), doutorado em Letras (Ciência da Literatura) pela Universidade Federal do Rio de Janeiro (1979) e pós-doutorado pela Universidade Federal do Rio de Janeiro (1997). Desenvolve pesquisas principalmente nos seguintes temas: cultura, Poética, história, crítica, teoria e Filosofia.

\section{MARIA ANTONIETA JORDÃO DE OLIVEIRA BORBA}

É professora do Departamento de Literatura Brasileira e Teoria da literatura da Universidade do Estado do Rio de Janeiro. Mestre em Letras pela Pontifícia Universidade Católica do Rio de Janeiro (1984), Doutora em Ciência da literatura pela Universidade Federal do Rio de Janeiro (1994) e pós-doutora em Filosofia pelo Departamento de filosofia da Pontifícia Universidade Católica do Rio de Janeiro, sob a supervisão do Professor Paulo Cesar DuqueEstrada. Atualmente é Pesquisadora visitante do Instituto de Letras da UERJ, na categoria Associado, atuando em regime de dedicação exclusiva nos cursos de pós-graduação em Letras. É coordenadora do Convênio de Cooperação Internacional entre a Pós-graduação de Letras da UERJ e o Department of Portuguese and Brazilian Studies da Brown University (EUA). Entre 1995 e 2003, foi docente do Departamento de Comunicação Social da Pontifícia Universidade Católica do Rio de Janeiro e do Instituto de Letras da UERJ. A partir de 2003, passou a dedicar-se exclusivamente à UERJ como bolsista do Prociência e pesquisadora do CNPq. Vem supervisionando pesquisas de Pós-doutorado e orientando teses de doutorado e dissertações de mestrado. Além da pós-graduação em Letras da UERJ, exerce atividades correlatas como membro do Laboratório de Pesquisa Interinstitucional Labelle, criado pela Professora Carmem Negreiros. Publicou três livros na área de Teoria da literatura, além de artigos em periódicos nacionais e internacionais. É membro do Conselho editorial/consultivo de revistas especializadas, sendo atualmente participante do Conselho Consultivo da Revista da ANPOLL. Vem realizando pesquisas no seguintes campos: Teoria do efeito e da recepção, Literatura comparada, em especial, na interrogação da Teoria da literatura com a Filosofia, a Estética 
da recepção, com destaque para estudos de interpretação, efeito, imaginário, desconstrução.

\section{MARIE-NOËLLE CICCIA}

Professora catedrática de Português (língua, literatura e civilização de Portugal e do Brasil) na Universidade Paul-Valéry (Montpellier, França), especializada em Estudos de Teatro português do século XVIII e em estudos de tradução. É autora dos livros Le théâtre de Molière au Portugal au XVIIIe siècle (2003) e Don Juan et le donjuanisme au Portugal du XVIIIe siècle à nos jours (2007). Editou as Actes du colloque international «Traduction et Lusophonie » (2007), além de dois números da revista Quadrant, Recherche en littérature Lusophone, $\mathrm{n}^{\circ} 25-26$, «Hommage au professeur Francis Utéza » (2009) e Quadrant, n²7, « Perméabilités dans les littératures et les arts des pays lusophones » (2010). Traduziu, em colaboração, o romance de Aquilino Ribeiro, $O$ Malhadinhas, para o francês (Les sentiers du démon, 2004).

\section{MÔNICA FIUZA BENTO DE FARIA}

Possui mestrado (1997) e doutorado (2003) em Letras pela Universidade Federal Fluminense. Atualmente é professor adjunto 3 da Universidade Federal do Rio Grande do Norte e professora em regime de colaboração técnica da Universidade Federal Fluminense. Atua na graduação na área de Letras, com ênfase em francês, língua e literaturas, ensino, avaliação, FOS e tradução. Coordena o setor de francês do LABESTRAD-Laboratório de Tradução da UFF. É formatrice labellisée TV5MONDE. Foi professora de francês do Colégio Santo Inácio RJ e do Colégio de Aplicação da PUC-RJ. Foi professora e coordenadora de francês do Liceu Franco Brasileiro RJ e da Aliança francesa do Rio de Janeiro, e diretora de duas filiais da AF do Rio de Janeiro, assim como, formadora e avaliadora do CIEP para os exames DELF/DALF. Participou do projeto Francês sem fronteiras, representando a UFRN. É membro da Associação de Professores de francês do Rio de Janeiro.

\section{PATRICIA MAROUVO}

Doutoranda em Letras pela Universidade Federal do Rio de Janeiro. Possui mestrado em Letras (2012) e graduação em Letras-Línguas e Literaturas de Português/Inglês (2009) pela Universidade Federal do Rio de Janeiro. Tem como foco de sua pesquisa a literatura de Virginia Woolf.

\section{RAFAELA SCARDINO}

Doutora em Letras/UFES (2015). Professora de Teoria Literária e Literaturas de Língua Portuguesa na Universidade Federal do 
Espírito Santo. Tem experiência na área de Letras, com ênfase em Teoria Literária, atuando principalmente nos seguintes temas: narrativa contemporânea, deslocamento, experiência e comunidades.

\section{RAPHAEL SALOMÃO KHEDE}

Possui graduação em Letras na Università degli Studi di Torino (2003), mestrado em Literatura Brasileira pela Universidade do Estado do Rio de Janeiro (2009) e doutorado em Literatura Comparada pela Universidade do Estado do Rio de Janeiro (2013). Foi professor adjunto de Língua e Literatura Italiana da Universidade Federal Fluminense (UFF). Atualmente, é professor de Língua e Literatura Italiana da Universidade Estadual do Rio de Janeiro (UERJ). Tem experiência na área de Letras, com ênfase em Língua e Literatura Italiana, Literatura Brasileira, Literatura Comparada e Tradução.

\section{RODOLFO MATA}

É pesquisador do Instituto de Investigaciones Filológicas da UNAM. Publicou, entre outros, Las vanguardias literarias latinoamericanas y la ciencia (2003), José Juan Tablada: letra e imagen (2003), CD ROM que contém o arquivo gráfico e a poesia visual do poeta mexicano, e De Coyoacán a la Quinta Avenida: José Juan Tablada, una antología general (2007). Prologou a reedição das memórias de Manuel Maples Arce (2010) e as edições fac-símiles de Un día..., El jarro de flores e La feria, de José Juan Tablada, e o livro de poesia visual Lugares donde el espacio cicatriza (2014), de Marco Antonio Montes de Oca. Organizou, traduziu e prologou antologias de escritores e críticos brasileiros, como Haroldo de Campos, Paulo Leminski, Rubem Fonseca, Dalton Trevisan e Antonio Candido. É coautor das antologias Ensayistas brasileños: literatura, cultura y sociedad (2005), Alguna poesía brasileña. Antología 1963-2007 (2009, reed. 2014) e La serpiente carnívora: catorce poetas surrealistas portugueses (2014). Seu ensaio “Divulgación de la ciencia: traducción, surrealismo y (auto) biografía" foi publicado recentemente no volume Narrar la ciencia (2014). Como poeta, publicou os livros Parajes y paralajes (1998), Temporal (2008) e Qué decir (2011). Seu poema eletrônico Silencio vacío acaba de ser publicado na Espanha por Uno y Cero Ediciones (http://unoyceroediciones.com/).

\section{SANDRA SOUSA}

É professora assistente de português na University of Central Florida (EUA). Graduou-se em Literatura e Cultura Portuguesa na Universidade de Lisboa (2001). É mestre em Estudos portugueses pela University of Massachusetts - Dartmouth (2006). É mestre (2011) e doutora (2012) em Estudos brasileiros e portugueses pela Brown 
University. É autora de Fiç̧ões do Outro: Império, Raça e Subjectividade no Moçambique Colonial (2015). Seus principais temas de pesquisa são: Colonialismo e pós-colonialismo; literatura colonial portuguesa; relações raciais em Moçambique; guerra, ditadura e violência nas literaturas portuguesa e africanas de língua portuguesa contemporâneas; escrita feminina nas literaturas portuguesa, brasileira e africanas de língua portuguesa.

\section{VAGNER CAMILO}

Professor associado 1 (livre-docente) de Literatura Brasileira da Universidade de São Paulo, com pesquisas voltadas para os seguintes temas relacionados à historiografia e à crítica literárias: poesia brasileira do século XIX, poesia brasileira do século XX (Carlos Drummond de Andrade, Jorge de Lima, João Cabral...), crítica de poesia (Sérgio Buarque de Holanda), recepção de idéias críticas no Brasil e relações entre lírica, história e sociedade. Possui graduação em Letras (Língua e Literatura Portuguesas) pela Pontifícia Universidade Católica de São Paulo (1988), mestrado em Teoria e História Literárias pela Universidade Estadual de Campinas (1993), doutorado em Teoria e História Literárias pela Universidade Estadual de Campinas (1999) e livre-docência em Literatura Brasileira pela Universidade de São Paulo (2013). É membro do projeto de pesquisa "La voz de los libros y el cambio digital. Figuras del archivo lingüístico-literario ibérico y brasileño de los siglos áureos a la actualidad", vinculado à Universidad de Salamanca, e responsável por dois convênios internacionais da FFLCH/USP, com a Universidade de Poitiers e com a Sapienza de Roma. É autor de Drummond: da Rosa do povo à rosa das trevas (2000). 